\title{
Large and Small Livestock Activities in Samsun Province
}

\author{
Hakan Guler \\ Faculty of Veterinary Medicine, Ondokuz Mayis University, \\ Department of Animal Health Economics and Management, Samsun, Turkey, \\ E-mail: hakanguler06@gmail.com
}

\begin{abstract}
In this study, the existence of bovine and ovine animals in Samsun province in the period between 2005 and 2019, emphasized the importance of the province in regional and country animal husbandry. During the said period, significant changes occurred in the bovine and ovine livestock assets and production of animal products of the province. In the province, while there has been an increase in the number of bovine animals, a relative decrease in the number of ovine animals was detected during the past period. In this development phase, projects and programs should be developed, the deficiencies of the current situation should be determined and supported with right and effective policies. The success of the sector will greatly contribute to the competitiveness of the region and the country's economy.
\end{abstract}

Keywords: Samsun City, Large Animals, Small Animals, Meat Production, Milk Production

DOI: $10.7176 / \mathrm{JSTR} / 6-13-07$

\section{Samsun İlinde Büyükbaş ve Küçükbaş Hayvancılık Faaliyetleri}

Özet

Bu çalışmada, 2005 - 2019 yılları arasındaki dönemde Samsun İli büyükbaş ve küçükbaş hayvan varlığ́ ile ilin bölge ve ülke hayvancılığındaki yeri ve önemi ortaya konulmuştur. Söz konusu dönem içerisinde ilin büyükbaş ve küçükbaş canlı hayvan varlığı ve hayvansal ürünlerinde önemli değişiklikler olmuştur. Geçen süreç içerisinde ilde büyükbaş hayvan sayısında artış görülürken, küçükbaş hayvan sayısında nispeten azalmanın olduğu tespit edilmiştir. Gelişen süreç ile birlikte mevcut durumun aksayan yönleritespit edilerek, doğru ve etkin politikalarla desteklenmeli, proje ve programlar geliştirilmelidir. Sektörün başarısı, bölgedeki rekabet gücüne ve ülke ekonomisine büyük ölçüde katkıda bulunacaktır.

Anahtar Kelimeler: Samsun İli, Büyükbaş Hayvancılık, Küçükbaş Hayvancılık, Et üretimi, Süt Üretimi

\section{Giriş:}

Geçmişten günümüze ülkelerin gelişme süreçlerinin ilk basamakları incelendiğinde bu ülkelerin kalkınma ve yolundaki öncelikli sektörünün sanayi ve hizmetler sektörü değil de, tarım ve hayvancılık sektörü olduğu tespit edilmiştir. Bunun temel sebebi; yüksek katma değere sahip mal ve hizmet üretiminin temel ihtiyacı olan hammadde kaynă̆ının yine tarım ve hayvancılık sektöründen temin ediliyor olmasıdır (İTB-2020).

Ülkemiz sahip olduğu iklim, toprak ve doğal kaynaklar ile hayvancılık sektörü için son derece elverişli ortam sunmaktadır. Özellikle büyük ve geniş ovaların varlığı, kaliteli, geniş çayır-meraların yoğunluğu, büyükbaş ve küçükbaş hayvancılığı için büyük imkan yaratmaktadır (Akpınar vd, 2012).

1980'li yıllara kadar ülkemizde sığır yetiştiriciliği daha çok aile işletmeciliği şeklinde yürütülmüş, 1980 yılından itibaren ise ekonomik büyüklüğe sahip sığırcılık işletmeleri şeklinde ortaya çıkmaya başlamış ve artık günümüzde devlet tarafindan sağlanan kredi, destek ve teşviklerin artması ile büyük kapasiteli modern sığırcılık işletmeleri şeklinde hızla çoğalmıştır (Hayvancılık Raporu, 2015).

Türkiye birçok alanda sahip olduğu gibi hayvancılık sektöründe de kaynakları tam kapasitesiyle kullanamayan ülkeler içerisindedir. (Hayvan Sitesi, 2020) Bu durum büyükbaş ve küçükbaş 
hayvancılık içinde geçerli olup, hayvancıllı̆ın geliştirilmesi için öncelikle büyükbaş hayvan soylarının ıslah edilmesi, temel girdi maliyetlerinin düşürülmesi ve hayvancılığın desteklenmesi gerekmektedir (Tapki,N.,vd.2018).

Yine son yıllarda küçükbaş hayvanlardan elde edilen kırmızı et üretiminin azalmasının nedeni olarak yoğun işgücü ve zaman olmak üzere, beslenmenin çayır ve meralardan elde edilmesi, örgütlenmenin yok denecek düzeyde az olması ve yetiştiriciliğin daha çok süt, peynir, yoğurt yün, yapağı gibi hayvansal ürünler için yapılması gösterilmiştir (Hayvancıllk Raporu, 2015).

$\mathrm{Bu}$ çalışmada Samsun İli'nin büyükbaş ve küçükbaş hayvancılık faaliyetleri çerçevesinde değerlendirilerek, sektörün durum tespiti ortaya konulmaya çalışılmıştır. Bu çerçevede elde edilen sonuçlar, hayvancılık sektörünün mevcut durumun iyileştirilmesi, büyükbaş ve küçükbaş hayvancılıkla ilgili güncel sorunların tespit edilmesi, sektörün gereksinimlerinin saptanması doğrultusunda oluşturulacak çalışmalarda altlık oluşturması bakımından fayda sağlayacaktır.

\section{Materyal ve Metot}

Araştırmanın materyalini Samsun İl Gıda Tarım ve Hayvancılık Müdürlüğü, Türk İstatistik Kurumu ile Orta Karadeniz Kalkınma Ajansı başta olmak üzere, çeşitli kurum ve kuruluşlara ait çalışma raporları ve istatistik verileri oluşturmuştur. Türkiye ve Samsun ilindeki büyükbaş ve küçükbaş hayvancilık işletmelerinin mevcut yapısal durumu ve üretim tespitinde Türk İstatistik Kurumu ve Samsun İl Gıda Tarım ve Hayvancılık Müdürlüğü verilerinden yararlanılmıştır.

Araştırmanın yönteminde; incelenen bütün çalışmanın sonuçlarından yola çıkılarak bir değerlendirme yapılmış, Samsun İli'nin büyükbaş ve küçükbaş hayvancılı̆ı̆na ait genel durumu ortaya konularak çeşitli öneriler sunulmuştur

\section{Bulgular}

Türkiye İstatistik Kurumu'nun(TÜIK) verilerine göre; 2004-2019 yılları arasında, Türkiye'de büyükbaş hayvan sayısı $\% 75,7$, küçükbaş hayvan sayısı da \% 52,3 oranında artış göstermiştir.

Tablo 1'de de görüldüğü gibi, Türkiye'deki toplam 17.872.331 adet büyükbaş hayvanın 381.912'si Samsun ilinde yer almaktadır Bu, Türkiye genelinde \% 2,14'lük bir oran anlamına gelmektedir.

Türkiye'deki toplam 48.481 .479 adet küçükbaş hayvanın (koyun/keçi) 224.621 adedi (\% 0,46) Samsun ilinde yer almaktadır. 2005 yılında 198.389 adet olan küçükbaş hayvan sayısı 2019 yılında \% 13,2 oranında bir artış göstererek 224.621' olmuştur.

Tablo 1. Samsun İli Büyükbaş ve Küçükbaş Hayvan Sayısı

\begin{tabular}{|l|c|c|c|c|c|c|}
\hline Yıllar & \multicolumn{2}{|c|}{ Türkiye } & \multicolumn{2}{c|}{ Samsun } & \multicolumn{2}{c|}{ Samsun (\%) } \\
\hline & Sığır & Koyun ve Keçi & Sığır & Koyun ve Keçi & Sı̆̆ır & Koyun ve Keçi \\
\hline 2005 & 10.631 .405 & 31.821 .789 & 295.743 & 198.389 & 2,78 & 0,62 \\
\hline 2010 & 11.454 .526 & 29.382 .924 & 293.873 & 145.469 & 2,57 & 0,50 \\
\hline 2015 & 14.127 .837 & $41.924,100$ & 310.849 & 204.168 & 2,20 & 0,49 \\
\hline 2019 & 17.872 .331 & $48.481,479$ & 381.912 & 224.621 & 2,14 & 0,46 \\
\hline Değişim (\%) & 68,1 & 52,3 & 29,1 & 13,2 & \multicolumn{2}{|c|}{} \\
\hline
\end{tabular}

Kaynak: TÜİK, Hayvansal Üretim İstatistikleri, 2020.

TR83 Bölgesi (Samsun, Tokat, Çorum, Amasya) illeri içinde en fazla büyük baş hayvana sahip il Samsun olurken, 309.371 adet küçükbaş hayvan sayısı ile Tokat ilinin komşu illere göre daha yüksek bir potansiyele sahip olduğu görülmektedir. Elde edilen bu sonuç aslında Türkiye genelinden farklı değildir. (Tablo 2) .

Tablo 2. TR 83 Bölgesi Büyükbaş ve Küçükbaş Hayvan Sayısı

\begin{tabular}{|l|c|c|}
\hline \multirow{2}{*}{ TR 83 Alt Bölgesi } & \multicolumn{2}{|c|}{ Hayvan Sayıları (2019) } \\
\cline { 2 - 3 } & Sı̆̆ır & Koyun ve Keçi \\
\hline Samsun & 381.912 & 224.621 \\
\hline Tokat & 313,346 & 378,219 \\
\hline Çorum & 246,598 & 254,200 \\
\hline Amasya & 192,846 & 215,671 \\
\hline
\end{tabular}

Kaynak: TÜIK, Hayvansal Üretim İstatistikleri, 2020.

53 | P a g e

www.iiste.org 
Türkiye İstatistik Kurumu'nun (TÜiK) verilerine göre 2005 yılından günümüze doğru sağılan büyükbaş hayvan ve küçükbaş hayvan sayılarını incelediğimizde düzenli bir artış olduğu görülmektedir.

2005-2019 yılları arasında; İnek sütü üretimi, Türkiye'de \% 177.4 oranında artarken, Samsun ilinde bu oran \% 51,6 oranında gerçekleşmiştir. Türkiye'de inek sütü üretimi 2005 yılında 10.026.202 ton iken 2019 yılında 20,782,374 ton olmuştur. Ülkemizde sığır sayısında meydana gelen istikrarlı artış ve yeni büyük tarımsal işletmelerin ekonomide faaliyete geçmesiyle süt üretimimizdeki bu devamın gittikçe artacağı görünmektedir.

Türkiye İstatistik Kurumunun 2019 verilerine göre Samsun ilinde; inek sütü üretimi, 2005 yılında 244.548 ton iken 2019 yılında 370,835 ton olmuştur. Manda sütü üretimi, 2005 y1lına göre \% 162,4 oranında bir artış göstererek 2019 y1lında 10,253 tona ulaşmaktadır.

Samsun İli küçükbaş hayvancılıkta; koyun sütü üretimi, 2005 yllında 6.378 ton iken 2019 yılında 9,123 tona ulaşırken, keçi sütü üretimi; 2005 yılında 465 ton iken 2019 yılında 1,107 tona olmuştur.

Tablo 3. Samsun İli Büyükbaş ve Küçükbaş Hayvansal Üretim (Ton)

\begin{tabular}{|c|c|c|c|c|c|c|c|c|c|c|c|c|}
\hline \multirow{2}{*}{ Yıllar } & \multicolumn{4}{|c|}{ Türkiye } & \multicolumn{4}{c|}{ Samsun } & \multicolumn{4}{c|}{ Samsun (\%) } \\
\cline { 2 - 13 } & $\begin{array}{c}\text { Inek } \\
\text { Sütü }\end{array}$ & $\begin{array}{c}\text { Manda } \\
\text { Sütü }\end{array}$ & $\begin{array}{c}\text { Koyun } \\
\text { Sütü }\end{array}$ & Keçi Sütü & Inek Sütü & $\begin{array}{c}\text { Manda } \\
\text { Sütü }\end{array}$ & $\begin{array}{c}\text { Koyun } \\
\text { Sütü }\end{array}$ & $\begin{array}{c}\text { Keçi } \\
\text { Sütü }\end{array}$ & $\begin{array}{c}\text { İnek } \\
\text { Sütü }\end{array}$ & $\begin{array}{c}\text { Manda } \\
\text { Sütü }\end{array}$ & $\begin{array}{c}\text { Koyun } \\
\text { Sütü }\end{array}$ & $\begin{array}{c}\text { Keçi } \\
\text { Sütü }\end{array}$ \\
\hline $\mathbf{2 0 0 5}$ & 10.026 .202 & 38.058 & 789.878 & 253.759 & 244.548 & 3.907 & 6.378 & 465 & 2,4 & 10,3 & 0,8 & 0,2 \\
\hline $\mathbf{2 0 1 0}$ & 12.418 .544 & 35.487 & 816.832 & 272.811 & 277.177 & 5.264 & 5.196 & 662 & 2,2 & 14,8 & 0,6 & 0,2 \\
\hline $\mathbf{2 0 1 5}$ & 16.933 .520 & 62.761 & 1.177 .228 & 481.174 & 278.714 & 8.873 & 8.511 & 1.058 & 1,6 & 14,1 & 0,7 & 0,2 \\
\hline $\mathbf{2 0 1 9}$ & 20.782 .374 & 79.341 & 1.521 .455 & 577.209 & 370.835 & 10.253 & 9.123 & 1.107 & 1,8 & 12,9 & 0,6 & 0,2 \\
\hline $\begin{array}{c}\text { Değiş̧im } \\
(\%)\end{array}$ & 107,2 & 108,47 & 92,6 & 127,4 & 51,6 & 162,4 & 43,0 & 138,0 & & & & \\
\hline
\end{tabular}

Kaynak: TÜIK, Hayvansal Üretim İstatistikleri, 2020.

TR83 Bölgesi (Samsun, Tokat, Çorum, Amasya) 1.136.725 ton süt üretimi ile ülke üretiminin yaklaşı \% 9'unu karşılamaktadır. TR83 bölgesinin toplamda en fazla süt üreten ili Samsun olurken, Tokat ilinin koyun sütü ve keçi sütü üretiminde komşu illere göre daha yüksek bir potansiyele sahip olduğu görülmektedir. (Tablo 4) .

Tablo 4. TR 83 Bölgesi Büyükbaş ve Küçükbaş Hayvansal Ürünler (Ton)

\begin{tabular}{|l|c|c|c|c|c|}
\hline & İnek Sütü & Manda Sütü & Koyun Sütü & Keçi Sütü & Toplam \\
\hline Samsun & 370,835 & 10,253 & 9,123 & 1.107 & $\mathbf{3 9 1 . 3 1 8}$ \\
\hline Tokat & 311,142 & 4,185 & 11,598 & 2,846 & $\mathbf{3 2 9 . 7 1 1}$ \\
\hline Çorum & 301,719 & 1,410 & 6,523 & 2,584 & $\mathbf{3 1 2 . 2 3 6}$ \\
\hline Amasya & 153,029 & 2,221 & 7,248 & 2,569 & $\mathbf{1 6 5 . 0 6 7}$ \\
\hline Toplam & $\mathbf{1 . 1 3 6 . 7 2 5}$ & $\mathbf{1 8 . 0 6 9}$ & $\mathbf{3 4 . 4 9 2}$ & $\mathbf{9 . 1 0 6}$ & $\mathbf{1 . 1 9 8 . 1 9 2}$ \\
\hline
\end{tabular}

Kaynak: TÜIK, Hayvansal Üretim İstatistikleri, 2020.

Samsun ilinde 2002 yılında 6.683 bin ton olan kırımızı et üretimi \% 44,2 artışla 2018 yllında 9.643 bin tona çikmıştır (Tablo 5).

Tablo 5. Samsun İli Kırmızı Et Üretim Miktarı (Ton)

\begin{tabular}{|l|c|c|c|c|c|c|}
\hline Yıllar & 2002 & 2015 & 2016 & 2017 & 2018 & 2002-2018 Değişim \\
\cline { 1 - 1 } $\begin{array}{l}\text { Kırmız1 } \\
\text { Et }\end{array}$ & 6.683 & 11.944 & 10.487 & 9.643 & 9.643 & 44,2 \\
\hline
\end{tabular}

Kaynak: GTHB, 2018. Samsun İl Müdürlüğü Kayıtları, Samsun

\section{Tartışma ve Sonuç}

Karadeniz Bölgesi'nin en büyük ve gelişmiş ili olan Samsun'da, özellikle 2000'li yılların ortalarından sonra büyükbaş hayvan varlığında gözle görülür bir artış yaşanmasına rağmen, küçükbaş hayvan varlığında yeterli düzeyde bir artış olduğunu söylemek mümkün değildir. 
Keçi varlığında meydana gelen artışa rağmen, koyun varlığında meydana gelen azalma, Samsun ilindeki küçükbaş hayvan varlığındaki düşüşün sebebi olarak görülmektedir.

Gelişen süreç ile birlikte sektörün bu anlamda desteklenmesi önem taşımaktadır. Burada esas olan amaç yalnızca hayvan sayısının fiziksel artırılması değil, Samsun ilindeki hayvancılık işletmelerin alt yap1 yetersizliklerini gidererek ihtisaslaşmasıdır.

Samsun ili sığır sayısı yönüyle önemli bir potansiyele sahiptir. Toplam sığır sayısı ve kültür melezi sığır sayısı yönünden komşu iller ve çevre bölgeler arasında üst sırada yer almasına rağmen, kültür ırkı sığır sayısı yönünden geride kalması Samsun ilinin ve içinde bulunduğu TR 83 bölgesinin birim sığır başına verimlilik değerlerini düşürmektedir. Bölgede et üretimindeki dalgalanma ve azalma Türkiye'ye oranla çok daha ortalama seviyededir. Et üretiminde ülkece yaşanan bu sıkıntı son dönemde et fiyatlarının oldukça ciddi bir şekilde artmasına neden olmuştur. En çok yerli ırk sığırlarına yönelik kesim yapılması birim hayvan başına et verimini etkileyerek düşürmüştür.

Büyükbaş hayvancılık sektöründe ıslah çalışmalarında önemli bir ilerleme sağlanmış olsa da, işletmelerin aile ekonomisine dayanan bir anlayış ile yetiştirme yapısına sahip olması ile üreticilerin hayvan beslemede profesyonel anlamda yeterince bilgi ve deneyime sahip olamamasindan dolayı elde edilen genetik potansiyelden yeterince yararlanmak mümkün olamamaktadır. $\mathrm{Bu}$ da maddi anlamda önemli ekonomik kayıplara neden olmaktadır

Samsun, manda varlığ bakımından incelendiğinde, yaklaşık 22.050 baş manda ile Türkiye'deki toplam manda sayısı bakımından birinci sırada yer almaktadır. 2008 yılından itibaren anaç mandalara yönelik devam eden desteklemeler devam ederken, geleneksel yöntemler kullanılarak gerçekleştirilmekte olan manda yetiştiriciliğinin artık sığır yetiştirmenin bir alternatifi olarak değil de, toplam hayvansal üretime katkı olacak yapıda düşünülmesi gerekmektedir.

Bafra ve Çarşamba ovaları hayvan yetiştiriciliği için bir avantaj teşkil etmektedir. Buna rağmen kültür ırk1 süt sığırcılığı, bölgede genellikle meraya dayalı sığırcılık yapılması nedeniyle ve yetiştiricilerin ürettikleri sütü pazarlama güçlüğü sebebiyle yeterince gelişmemiştir. Sürekli artan yem maliyetleri özellikle besi hayvanlarının verimlerini düşürmektedir. Yem bitkileri üretimine gereken önemin ivedilikle verilmesi, kaba yem üretiminin artırılması bu bakımdan çok büyük önem taşımaktadır.

Samsun İli, TR83 Bölgesindeki diğer komşu iller ile karşılaştırıldığında, büyükbaş hayvan varlığ bakımından birinci sırada olmasına karşın, küçükbaş hayvan varlığı bakımından sonlara doğru kendine bir yer edinmiş olduğu görülmektedir. Bu durum aslında Samsun'da, büyükbaş hayvansal üretim alanında büyük bir potansiyel olduğunu ortaya koymaktadır. Nitekim, hayvancılık alanında yapılacak olan destek ve teşvikler sektörün daha çok gelişmesine neden olurken, et ve süt ürünleri işleme ve paketleme sektörlerine yönelik yapılacak sanayi yatırımları, sektörün daha fazla büyümesine katkıda bulunacaktır. Bu durum hem Samsun ilinin, hem de bölgenin ekonomik refahını yükseltecek, ülkemiz için de kalkınmayı hızlandıracaktır.

Samsun ilinde hayvancılık sektöründe yaşanan en önemli sorunlardan biri de; üretim ve pazarlama sürecinde yaşanan işbirliği ve dayanışma eksikliğidir. Yetiştiriciler kasaplık olarak yetiştirilen hayvanların pazarlanması konusunda önemli sıkıntılar yaşarken, üreticiler de benzer şekilde ürettikleri sütlerin pazarlanması konusunda ciddi zorluklarla karşılaşmaktadırlar. Samsun'daki et ve süt işleme tesislerinin bölgedeki diğer yakın illerle kıyaslandığında, gerek sayı, gerekse kapasite olarak yeterli olmaması bu sorunu önemli boyutlara taşımaktadır. Entegre et ve süt işleme tesislerinin hem rakam hem de kapasite olarak çoğaltılması bu sorunların giderilmesine katkı sağlayacaktır.

Çalışmanın sonuçları bütün olarak değerlendirildiğinde, Samsun ili büyükbaş ve küçükbaş hayvancılığında aksayan yönleri doğru ve etkin politikalarla desteklenmeli, yetiştiricilerin bilinçlendirilerek örgütlenmesi için programlar geliştirilmelidir. Nihayetinde; girdi üretiminden, pazarlamaya kadar ki bu süreçte elde edilecek başarı, sektörün bölgedeki rekabet gücüne büyük ölçüde katkı sağlayacaktır.

\section{Kaynaklar}

Akpınar, R., Özsan, M. E., Taşçı, K. (2012). Doğu Anadolu Bölgesi’nde Hayvancılık Sektörünün Rekabet Edebilirliğinin Analizi. Gümüşhane Üniversitesi Sosyal Bilimler Elektronik Dergisi, Say1: 5 ss. 199-200

GTHB, (2018). Gıda Tarım ve Hayvancılık Bakanlığı, Samsun İl Müdürlüğü Kayıtları, Samsun.

55 | P a g e

www.iiste.org 
Hayvan Sitesi, (2020). https://www.hayvansitesi.com/hayvancilik/turkiyede-buyukbas-hayvancilik/ (Erişim tarihi 15.11.2020)

Hayvancılık Raporu 2015 (2014) T.C. Gıda Tarım ve Hayvancılık Bakanlığı, GAP Uluslararası Tarımsal Araştırma ve Eğitim Merkezi, Aralık, Yıl:2 Sayı:2

İTB (2020). İzmir Ticaret Borsası, https://itb.org.tr/Sayfa/121-buyukbas-kucukbas-hayvan-varligive-sut-uretimi-mevcut-durumu-turkiye--izmir Erişim Tarihi 11.09.2020

Tapki,N., Kaya, Aybuke.,Tapki, İ.,Dagistan,E., Cimrin, T.,Selvi, M. H., (2018). Türkiye'de Büyükbaş Hayvancılığının Durumu ve Yıllara Göre Değişimi, Mustafa Kemal Üniversitesi, Ziraat Fakültesi Dergisi, 23 (2),324-339

TÜİK (2020) Türkiye İstatistik Kurumu, Hayvancılık İstatistikleri https://data.tuik. gov.tr/Kategori/GetKategori?p=tarim-111\&dil=1 Erişim Tarihi 11.11.2020 